\title{
Thermohydraulic Performance of a Channel Employing Wavy Porous
}

\section{Screens}

\author{
L. Cramer \\ u11020149@tuks.co.za
}

\author{
Gazi I. Mahmood* \\ gazi.mahmood@up.ac.za
}

J.P. Meyer

josua.meyer@up.ac.za

Mechanical and Aeronautical Engineering Department, University of Pretoria, South Africa.

\begin{abstract}
Porous inserts are commonly employed in the heat exchanger channels to enhance the thermal performance. The present experimental investigations measure the pressure drop and heat transfer in a rectangular channel that employs porous screen mesh in the sinusoidal shape as inserts. Four screens with different forms of sinusoidal wave are employed: $68 \%$ porosity$12 \mathrm{~mm}$ period, $48 \%$ porosity- $12 \mathrm{~mm}$ period, $68 \%$ porosity- $18 \mathrm{~mm}$ period, and $48 \%$ porosity$18 \mathrm{~mm}$ period. The peak-to-peak height of the wave is $5 \mathrm{~mm}$ and touches the channel walls along the wave vectors that are parallel to the mean flow. Measurements in the smooth channel are used to normalize the friction factors and Nusselt numbers in the screen channel and provide the enhancements of friction factors $\left(f / f_{0}\right)$ and Nusselt numbers $\left(\mathrm{Nu} / \mathrm{Nu} u_{0}\right)$ due to the screens. The Reynolds number $(R e)$ based on the channel hydraulic diameter varies between 400 and 11,000. The results indicate the friction factor $(f)$, average Nusselt number $(N u), N u / N u_{0}$, and $f / f_{0}$ in the screen channel depend strongly on the $R e$. The screen porosity and wave period effects are significant on the $f$ and $f / f_{0}$ only. The thermal performance index, $\left(N u / N u_{0}\right) /\left(f / f_{0}\right)^{(1 / 3)}$
\end{abstract}

\footnotetext{
*Corresponding author, Phone: +27 124206822.
} 
is also influenced strongly by the $R e$. The present results thus indicate the viability of the wavy porous inserts for the heat exchangers.

Keywords: Friction factor ratio, Nusselt number ratio, Thermal performance, Porosity, Wave period.

\section{Nomenclature}
$\left(\mathrm{A}_{\mathrm{c}}, \mathrm{D}_{\mathrm{h}}\right)$
channel cross-sectional area, hydraulic diameter
$\left(\mathrm{C}_{\mathrm{p}}, \mathrm{k}_{\mathrm{a}}\right)$
(specific heat, thermal conductivity) of air
friction factor in screen channel
$(\mathrm{H}, \mathrm{L}, \mathrm{W})$
(height, length, width) of test section
$\mathrm{m}_{\mathrm{a}}$
mass flow rate of air
$\mathrm{Nu}$
Nusselt number
$\left(\mathrm{P}_{\mathrm{x}}, \mathrm{P}_{0}, \mathrm{P}^{*}\right)$
Pressure: local wall-static, reference, normalized on wall
$\left(\mathrm{Q}_{\mathrm{c}}, \mathrm{Q}_{\mathrm{c}, \mathrm{x}}\right)$
(total convective power, local convective power) on surface
$\operatorname{Re} \quad$ Reynolds number, $\left(\frac{m_{a} D_{h}}{A_{c} \mu_{a}}\right)$
$\left(\mathrm{T}_{\mathrm{a}, \mathrm{in}}, \mathrm{T}_{\mathrm{m}, \mathrm{x}}, \mathrm{T}_{\mathrm{w}, \mathrm{x}}\right) \quad$ Temperature: inlet air, local bulk-mean of air, on wall at distance $\mathrm{X}$
$\mathrm{U}$
mean flow velocity, $\left(\frac{m_{a}}{A_{c} \rho_{a}}\right)$
$(\mathrm{X}, \mathrm{Y}, \mathrm{Z}) \quad$ Cartesian coordinate system

\section{Greek Symbols}

$\Delta$

$\left(\mu_{\mathrm{a}}, \rho_{\mathrm{a}}\right)$

$(\lambda, \zeta)$ difference between two quantities

(dynamic-viscosity, density) of air

(wave period, porosity) of sinusoidal screen 


\section{Subscripts and Superscripts}
$\operatorname{avg}$
average property
$\mathrm{X}$
local property on the wall along $\mathrm{X}$
0
reference or smooth channel property

\section{Introduction}

Channels in the heat exchangers, cooling jackets of machine components, cooling base of fuel cells and electronic components, solar heater panels, and photovoltaic modules employ internal fins, porous metal foams, and mesh inserts to enhance the convection heat transfer. Recently, the internal porous fins and porous foams of high thermal conductivity have gained considerable attentions in the research and development for their light weight, reduced fluid pumping power requirements, and high heat transfer characteristics. The porous materials in the channels are treated as the fins because of the significant surface contacts the material makes with the channel walls. However, as the fluid passes through the tortuous channels of the pores in the fins and foams, the enhancement of heat transfer relative to the pumping power known as the thermal performance suffers. Consequently, the porous fins and foams are sometimes unsuitable in many low Reynolds number applications. The present research investigates the wavy porous screens in a heat transfer channel as an alternative to the porous foams and fins. The wave vectors of the screen are arranged parallel to the channel mean flow and channel walls. The tips of the wave make only line contacts with the walls along the channel without any bonding. Without a significant surface contact, the porous waves create the local turbulence for the heat transfer enhancement without being the internal extended surfaces. The pores in the thin screen volume are perpendicular to the flow direction. The bulk of the fluid then flows between the screen walls of the wave with little blockage offered by the 
screen volume. The wave structure of the screen at the contact locations with the channel can also provide the structural support to the walls for some heat exchanger applications with the flat-plate and annular channel constructions.

The effects of different configurations of surface roughness and internal fins on the convective heat transfer, flow structure, and pressure drop in channels have been summarized by Webb and Kim (2005). The channel internal structures augment both the heat transfer and pressure penalty as explained by Webb and Kim (2005) due to the formation of local flow unsteadiness and agitated boundary layer near the channel walls. Augmentations of the convection heat transfer at the channel wall and pressure drop along the channel filled with the porous foams are investigated by Chen et al. (2013), Alhusseny et al. (2015), Lu et al. (2016), Part et al. (2016), Wang et al. (2015), Kim et al. (2000), Mohammadian and Zhang (2016), and Mohammadian et al. (2015) in the recent years. The foam materials fill in the channel flow space either partially or completely as a single block or multiple sections in the investigations. The results in Chen et al. (2013), Alhusseny et al. (2015), Lu et al. (2016), Part et al. (2016), Wang et al. (2015), and Kim et al. (2000) are provided for low Reynolds numbers with varying porosities of the materials and show both the heat transfer coefficients and pressure drop increase along the channel significantly as the foam-porosity is reduced. Mohammadian and Zhang (2016), Mohammadian et al. (2015), and Maerefat et al. (2011) report that the material and thickness of porous matrix embedded in channel influence the flow-temperature uniformity and pressure penalty of the channel. The pore geometry of packed bed in a two-dimensional channel is optimized by Hobold and da Silva (2017) to affect the thermal boundary layer on the walls and maximize the heat transfer coefficient. The periodic arrangements of the porous fins and baffles between the parallel walls of two-dimensional channels investigated by Hamdan and Al-Nimr (2010), Davari and Maerefat (2016), and Santos and de Lemos (2006) cause the enhancement of the heat transfer coefficients with some reduction in the friction 
factors relative to the solid fins and baffles. The thermal performance of the studies are dependent on the fin or baffle geometry and porosity. The investigations of Pavel and Mohamad (2004a, 2004b) employ the metal mesh screens in multiple layers as inserts perpendicular to the flow direction to augment the heat transfer coefficients with the minimal effects on the pressure drop in tubes. The mesh inserts of Pavel and Mohamad (2004a, 2004b) increase the heat transfer by undulating the flow velocity near the wall unlike the extended fin surfaces.

Kays and London (1964) provide experimental friction factors and heat transfer coefficients in a flat-plate channel with perforated wavy internal-fins of porosity $16 \%$. The tips of the fin-wave are soldered to the channel walls. The flow passes between the fin walls unlike the other porous fins and foams mentioned earlier. Mahmood et al. (2015) report the thermal performance in a rectangular channel employing a sinusoidal screen of high porosity for low Reynolds number applications. The wave vectors of the screen in Mahmood et al. (2015) is parallel to the flow, but make only line contacts with the channel walls at the tips without any bonding. The investigations of Torii and Yang (2007) show the perforations in flat-plate parallel to the channel flow induce local turbulence. The heat transfer enhancements with the small increase in friction factors in Kays and London (1964) and Mahmood et al. (2015) can be explained by such local flow perturbations (Torii and Yang, 2007) formed by the small pores.

The present investigations employ four wavy porous screens of two different porosities and two different wave periods in a rectangular channel and measure the heat transfer coefficients and friction factors as the flow Reynolds number ranges from the laminar to turbulent. The effects of porosity and wave period of the sinusoidal screen in the transition and turbulent regimes of $R e$ on the $N u$ and $f$ in the investigations of Mahmood et al. (2015) are absent. The results from the present investigations are presented relative to those in a smooth 
channel to show the enhancement of heat transfer coefficients and friction factors with the wavy screens. The objectives are to quantify the thermal performance of the channel employing the wavy porous screens for a wide range of applications. Unlike the porous foams and fins, the results presented here are independent of the material of the wavy screen that does not serve as fins due to the line contacts and no bonding with the channel walls as indicated earlier.

\section{Experimental Setup and Methods}

The experimental measurements are obtained in a low-speed air-channel test facility shown schematically in Fig. 1(a). The ambient laboratory air is drawn through the channel and test section using a centrifugal blower. The air accelerates smoothly through a two-dimensional contraction section of contraction ratio $27: 1$ before entering the $2.0 \mathrm{~m}$ long flow development section. The length of the flow development section is dictated by the laminar $R e$. The air-flow then enters the test section of length $0.50 \mathrm{~m}$ following an extension of length $0.50 \mathrm{~m}$ and a large plenum box. From the exit of contraction to the inlet of plenum, the channel maintains a uniform rectangular cross-section of aspect ratio 1:41 and height $5 \mathrm{~mm}$. The channel walls are manufactured from the commercial acrylic plastic of thickness $10 \mathrm{~mm}$. As shown in Fig. 1(a), air from the plenum flows through two metered-pipes connected to the blower on the other ends. The ISO 5167-1980 (International Standard, 1980) orifice plates in the pipe sections are connected to the differential pressure transducers to provide the mass flow rate in the airchannel. A variable speed drive is used to control the blower speed and mass flow rate. The sealant at the seams between the adjacent channel sections prevent any air leaks into the channels.

In order to measure the pressure drop, one of the $203 \mathrm{~mm}$ wide walls of the test section is tapped with $0.3 \mathrm{~mm}$ holes. The thirty-three pressure taps are located at $15 \mathrm{~mm}$ apart from one another along the test section and connected to a mechanical scanner and then to a differential pressure transducer with the plastic tubes. For heat transfer measurements, the $203 \mathrm{~mm}$ wide 


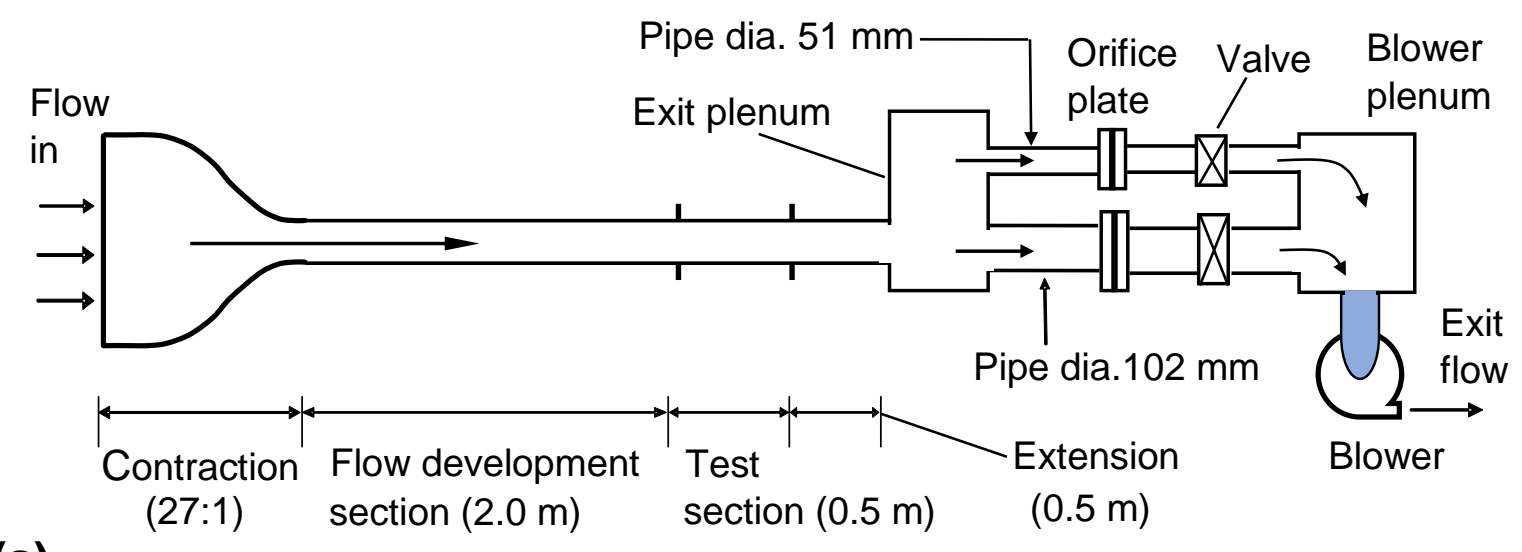

(a)

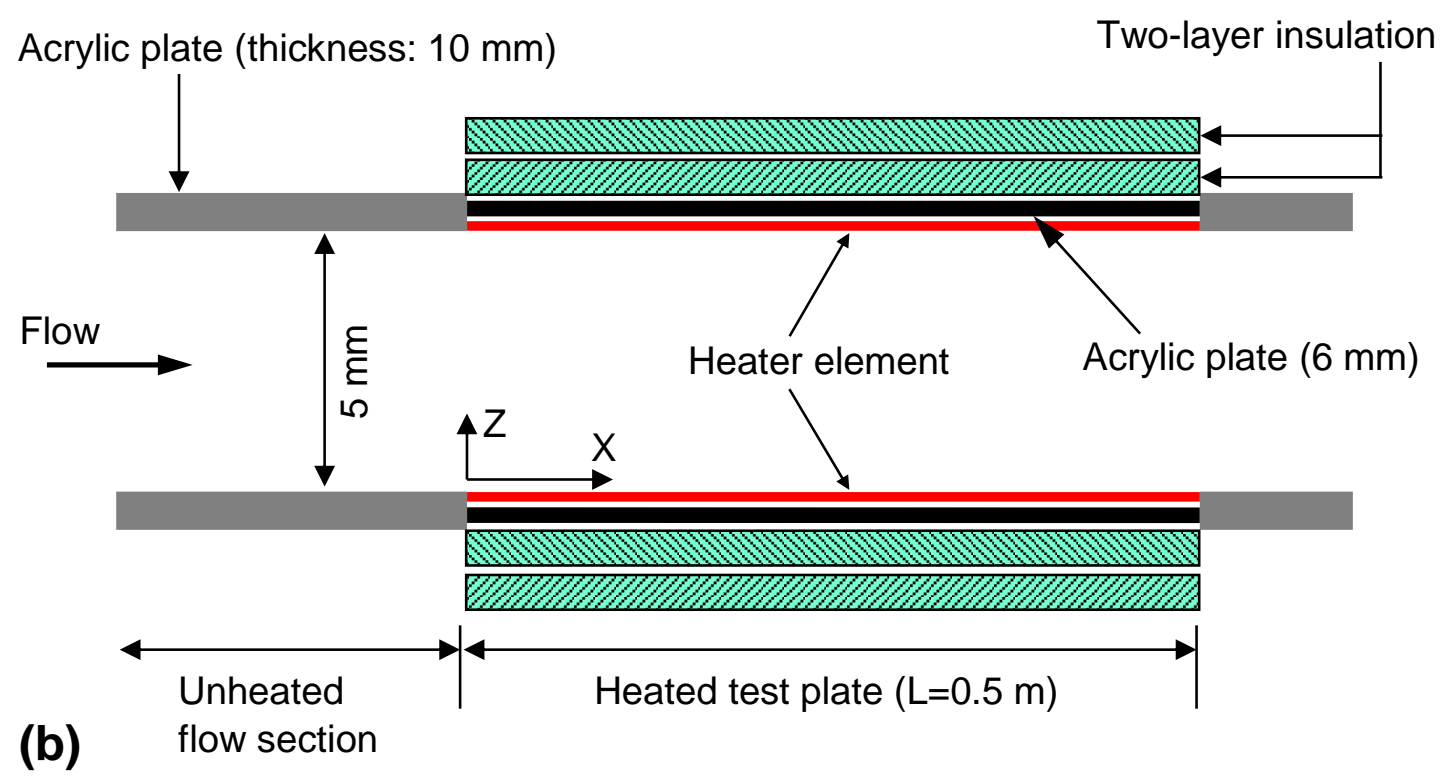

Figure 1: Schematic of: (a) experimental air channel (elevation view), and (b) test section wall heater arrangements (not drawn to scale). 
walls are replaced by $203 \mathrm{~mm}$ wide by $6 \mathrm{~mm}$ thick acrylic walls with the thin film-heaters attached along the length on the flow side. The commercial film-heaters are comprised of the Kapton $^{\mathrm{TM}}$ encapsulated Inconel heating elements. A thin layer of copper tape covers the heater to provide continuous heat flux to the air-flow. The heated walls are insulated with two layers of insulation foams. Figure 1(b) shows the arrangements of the heat transfer test section and the coordinate systems employed for the measurements. The distance between the heated walls is adjusted to make the heater side flush with the other channel walls. The heated walls are instrumented with the thermocouples at the locations shown in Fig. 2. Thermocouples are also placed inside the insulation layers. The wall-thermocouples are only placed in one wall and in contact with the heater through drilled holes for the temperature measurements on the heated surface. The insulation thermocouples provide the temperature measurements for the conduction power losses from the heaters. The spacing between wall-thermocouples is either $15 \mathrm{~mm}$ or $10 \mathrm{~mm}$ depending on their locations from the plate trailing-edge. Figure 2 excludes the thermocouples placed in contact with the heater in the plate upstream-half along the middle at $Y=101.5 \mathrm{~mm}$. The details of the thermocouple placements are further illustrated in Mahmood et al. (2015).

The measurements of pressure drop are obtained at the ambient isothermal condition and of heat transfer are based on the average convective heat flux from each heated wall. The filmheaters employed on the two walls have identical resistance and are connected in series. Power to the heaters is then supplied from a single DC power source to ensure the same power input level is used to the heaters. The signals from the pressure transducers and thermocouples are digitized with a National Instrument data acquisition system and then recorded via a Labview ${ }^{\mathrm{TM}}$ computer program. The data from each acquisition channel are acquired at $500 \mathrm{~Hz}$ for 2 seconds for the temperature and at $100 \mathrm{~Hz}$ for 2 seconds for the pressure. The signals are then timeaveraged and converted into degree Celsius and Pascal after applying the appropriate 


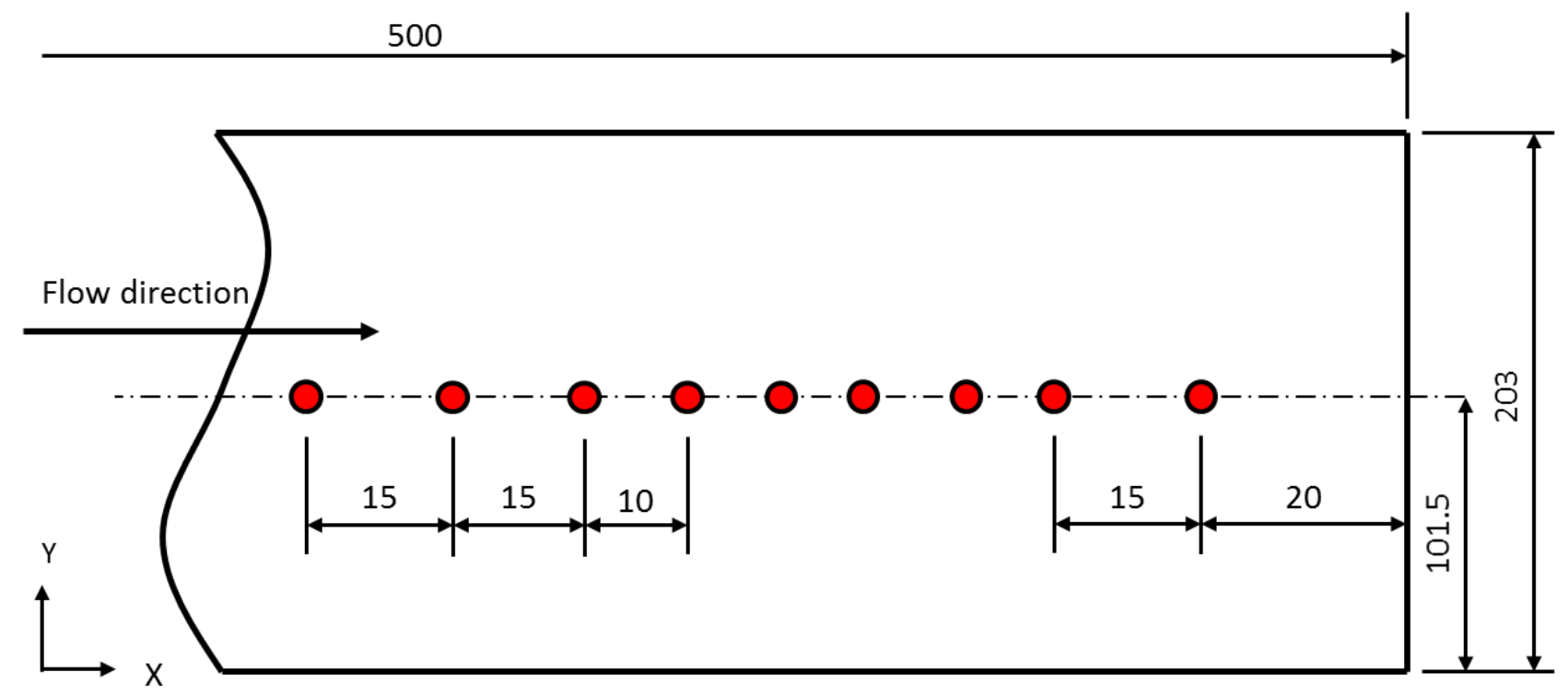

Figure 2: Plan view of thermocouple tip locations along test wall (dimensions are in $\mathrm{mm}$ ). 
calibration curves. The discharge coefficients of the orifice plates are determined from the Stolz's equation in (International Standard, 1980) through iterations using the orifice pressuredifference. The ideal gas law is used to estimate the air-density for the mass flow measurements. A thermocouple located at the test section inlet measures the temperature, $T_{a, i n}$. The energy balance in Eq. (1) is used to estimate the local mean temperature, $T_{m, x}$ along the test channel. The specific heat, $C_{p}$ in the equation and thermal conductivity of air, $k_{a}$ are estimated at $T_{a, i n}$ as the maximum difference of $\left(T_{w, x}-T_{a, i n}\right)$ is $35^{\circ} \mathrm{C}$ and $\left(T_{m, x}-T_{a, i n}\right)$ is $15^{\circ} \mathrm{C}$ at the exit.

$$
T_{m, x}=T_{a, i n}+\frac{\Sigma Q_{c, x}}{\left(m_{a} \cdot C_{p}\right)}
$$

The heat transfer measurements are obtained either with the two walls in Fig. 1(b) heated or with only one wall heated. The thermal boundary layer only starts to develop when the ambient air enters the test section. As the film-heaters are attached to the plates on the airstream side and the outer sides of the plates are insulated, it can be assumed that most of the heat is transferred to the air-flow through the convection and only a small amount is lost through the conduction in the walls. A one-dimensional conduction analysis is applied based on the temperature differences across the insulation layers to determine the conduction losses. Further details of the conduction loss analysis are provided in Mahmood et al. (2015). The maximum conduction loss from each heated wall is found to be less than $5 \%$ of the total power input to the film-heater. The convective power, $Q_{c}$ into the flow from a plate is then calculated subtracting the conduction losses from the total power input to the heater. Heat loss due to the radiation is neglected because the maximum temperature difference between the heated wall and ambient is less than $35^{\circ} \mathrm{C}$. The total power, $\sum Q_{c, x}$ in Eq. (1) is the total convective power from either two heated plates or one heated plate over the length $X$ in the test section. The local Nusselt number, $N u_{x}$ at a thermocouple location is then determined from the average convective 
heat flux, $Q_{d}(L . W)$ on the test surface as in Eq. (2). All the measurements are obtained in the test section with and without the porous screen at different $R e$. The friction factors, $f_{0}$ measured in the smooth test section without the screen differ by less than $5 \%$ from the analytical friction factors in the smooth channel (Kays and Crawford, 1993). The fully-developed Nusselt numbers, $\mathrm{Nu}_{0}$ measured in the smooth test section differ by less than $10 \%$ in the laminar $R e$ and less than $5 \%$ in the turbulent $R e$ from the analytical ones in the smooth channel (Kays and Crawford, 1993).

$$
N u_{x}=\frac{\left(Q_{c} \cdot D_{h}\right)}{\left[(L . W) \cdot\left(T_{w, x}-T_{m, x}\right) \cdot k_{a}\right]}
$$

\section{Mesh-Screen Geometry}

The wavy porous screens are formed in-house from the commercial flat mesh screens. The stainless steel wires of diameter $0.28 \mathrm{~mm}$ are interweaved to generate the square pores of the mesh in the screen. A pair of identical bending jigs is used to form-press the sinusoidal shape of the screen. The jigs are laser cut to the required sinusoidal shape from metal plates. The screen is laid flat on one jig while the other jig is pressed down onto the screen using a hand press. Sufficient tolerances in the jigs allow the screen to deform into the sinusoidal wave of period $12 \mathrm{~mm}$ or $18 \mathrm{~mm}$ and of height $5 \mathrm{~mm}$ peak-to-peak after some spring back of the screen material. Different jigs are employed to form the two wave periods of $12 \mathrm{~mm}$ and $18 \mathrm{~mm}$. Figure 3(a) shows an image of the final sinusoidal form of a mesh screen. Two flat screens of mesh porosity $48 \%$ and $68 \%$ are employed in each of the formed sinusoidal wavy screens. Thus, four wavy screens are tested: $68 \%$ porosity- $12 \mathrm{~mm}$ period, $48 \%$ porosity- $12 \mathrm{~mm}$ period, $68 \%$ porosity- $18 \mathrm{~mm}$ period, and $48 \%$ porosity- $18 \mathrm{~mm}$ period. The square pores have an aperture of $0.57 \mathrm{~mm}$ for the $48 \%$ porosity mesh and an aperture of $1.31 \mathrm{~mm}$ for the $68 \%$ porosity mesh before the bending. The number of pores per $25.4 \mathrm{~mm}$ is about 31 for the $48 \%$ porosity mesh and 16 for the $68 \%$ porosity mesh. Figure 3(b) shows the wave geometry of the 


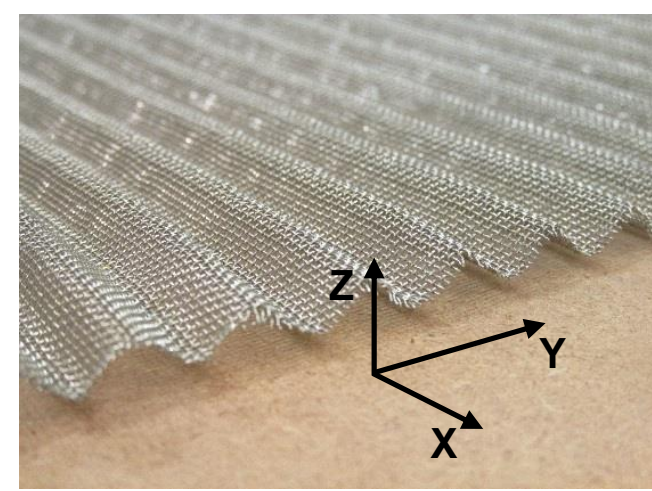

(a)

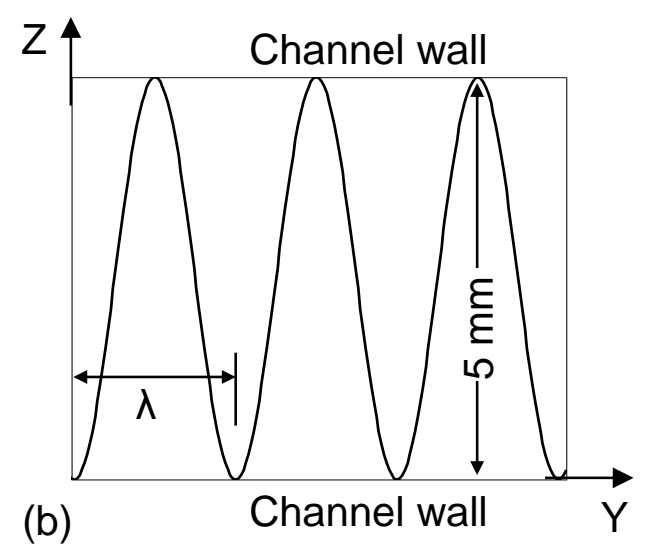

Figure 3: (a) Image of an actual sinusoidal screen, and (b) schematic of the screen sinusoidal wave in YZ-plane, $\lambda=12 \mathrm{~mm}$ or $18 \mathrm{~mm}$ (X: mean flow direction). 
sinusoidal screens. The screen wave-period is oriented along the $203 \mathrm{~mm}$ width ( $Y$-direction) while the wave-vector is along the mean flow ( $X$-direction) of the channel.

The wavy screen is inserted into the test channel by removing a wall of the channel. A visual inspection is done to check for the contacts between the tips of the wave and channel walls. The tips make only line contacts with the walls along the wave vector. The tips are not soldered or bonded to the walls making the wavy screens easily replaceable. Because of the stiffness and unevenness in the screen, there are some locations where the wave-tips may not contact the walls. As the screen insert affects the convective heat transfer by promoting the local turbulence, contact points with the heated surface are not important for the heat transfer enhancements as opposed to the fins. The screen placement inside the test section ensures that no pressure tap and wall-thermocouple positions fall under the wave tips. The porous screen offers two distinct structural advantages: (i) it is lighter in weight than the porous foams, and (ii) it makes the channel construction modular in the heat exchangers as it can be replaced easily.

\section{Uncertainty Estimates}

The uncertainties in the measured data are estimated based on the $95 \%$ confidence interval and the errors in the computed values are determined based on the propagation of uncertainties in Beckwith et al. (2007) and Moffat (1988). The maximum uncertainty in the thermocouple temperature is $\pm 1.0{ }^{\circ} \mathrm{C}$. The uncertainty of $Q_{c}$ is $4 \%$ and $3 \%$ of the total heater power at $R e=$ 400 and 11,000, respectively. The uncertainty in the wall static pressure is $2.5 \mathrm{~Pa}$ at $R e=400$ and $13.0 \mathrm{~Pa}$ at $R e=11,000$ at locations $X / L \geq 0.9$. The uncertainty in the mass flow rate measurement is $2 \%$. The uncertainty in the calculated $f$ is then $8 \%$ at $R e=400$ and $2 \%$ at $\operatorname{Re}=$ 11,000 . The high uncertainty in the friction factor at low $R e$ is caused by the low pressure drop in the channel. The calculated $N u$ has an uncertainty of $7 \%$ at $R e=400$ and $4 \%$ at $R e=11,000$. To account for any inconsistency with the in-house forming of the screen waves, three samples 
of the wavy screen of each porosity are tested. The variations of the friction factors and Nusselt numbers between the screen samples are found to be less than $5 \%$.

No geometric changes are expected in the wavy screens after the tests at low elevated wall temperatures $\left(60^{\circ} \mathrm{C}\right.$ and below) because of the insignificant thermal expansion of the stainless steel material of the screen. Also, the wave forms of the screens are not deformed in the channel as the wave height (peak-to-peak) is same as the channel height. Results from some repeated tests with a wavy screen by placing and replacing it few times in the channel fall within the uncertainties reported above.

\section{Discussions of Results}

Measured data are reported at the steady-state test conditions considered when the temperatures and surface pressures vary by less than $0.1^{\circ} \mathrm{C}$ and $2 \mathrm{~Pa}$, respectively, over a period of 10 minutes. The air flow is assumed incompressible due to the small range of velocity (less than $20 \mathrm{~m} / \mathrm{s}$ ), pressure drop (less than $5.0 \mathrm{kPa}$ ), and wall temperature (less than $60{ }^{\circ} \mathrm{C}$ ) used during the measurements. The test conditions for all the measurements are summarised in Table 1. The heat flux in the table is based on the average convective heat flux from a heated wall. The air viscosity and density $\left(\mu_{a}, \rho_{a}\right)$ are estimated at $T_{a, i n}$. The flow becomes hydrodynamically fully-developed in the $2.0 \mathrm{~m}$ long channel upstream of the test section at all $R e$. Heat transfer measurements are obtained with the two-walls in Fig. 1(b) heated as well as one-wall heated keeping the other $203 \mathrm{~mm}$ wide wall adiabatic. The measurements in the smooth channel without the screen will be referred to as the baseline data.

\subsection{Pressure Drop and Friction Factor}

The pressure drop coefficients, $\Delta P^{*}$ along the $X / L$ direction are shown for the $68 \%$ porosity screen in Fig. 4 with $12 \mathrm{~mm}$ wave period. The $\Delta P^{*}$ coefficients are determined from Eq. (3). The values of $\Delta P^{*}$ are negative because the difference $\left(P_{x}-P_{0}\right)<0$ increases along the channel. The reference pressure, $P_{0}$ in Eq. (3) is obtained at $10 \mathrm{~mm}$ downstream from the test section 
Table 1. Test conditions

\begin{tabular}{cccccc}
\hline \hline $\mathrm{U}(\mathrm{m} / \mathrm{s})$ & $\mathrm{Re}$ & $\begin{array}{c}\text { Heat flux } \\
\left(\mathrm{W} / \mathrm{m}^{2}\right)\end{array}$ & $\begin{array}{c}\mathrm{C}_{\mathrm{p}} \\
(\mathrm{J} / \mathrm{kg} . \mathrm{K})\end{array}$ & $\rho_{\mathrm{a}}\left(\mathrm{kg} / \mathrm{m}^{3}\right)$ & $\begin{array}{c}\mathrm{T}_{\mathrm{a} \text {,in }} \\
\left({ }^{\circ} \mathrm{C}\right)\end{array}$ \\
\hline $0.74-19.0$ & $400-11,000$ & $14.0-183$ & 1005 & $1.00-1.12$ & $20-28$ \\
\hline \hline
\end{tabular}




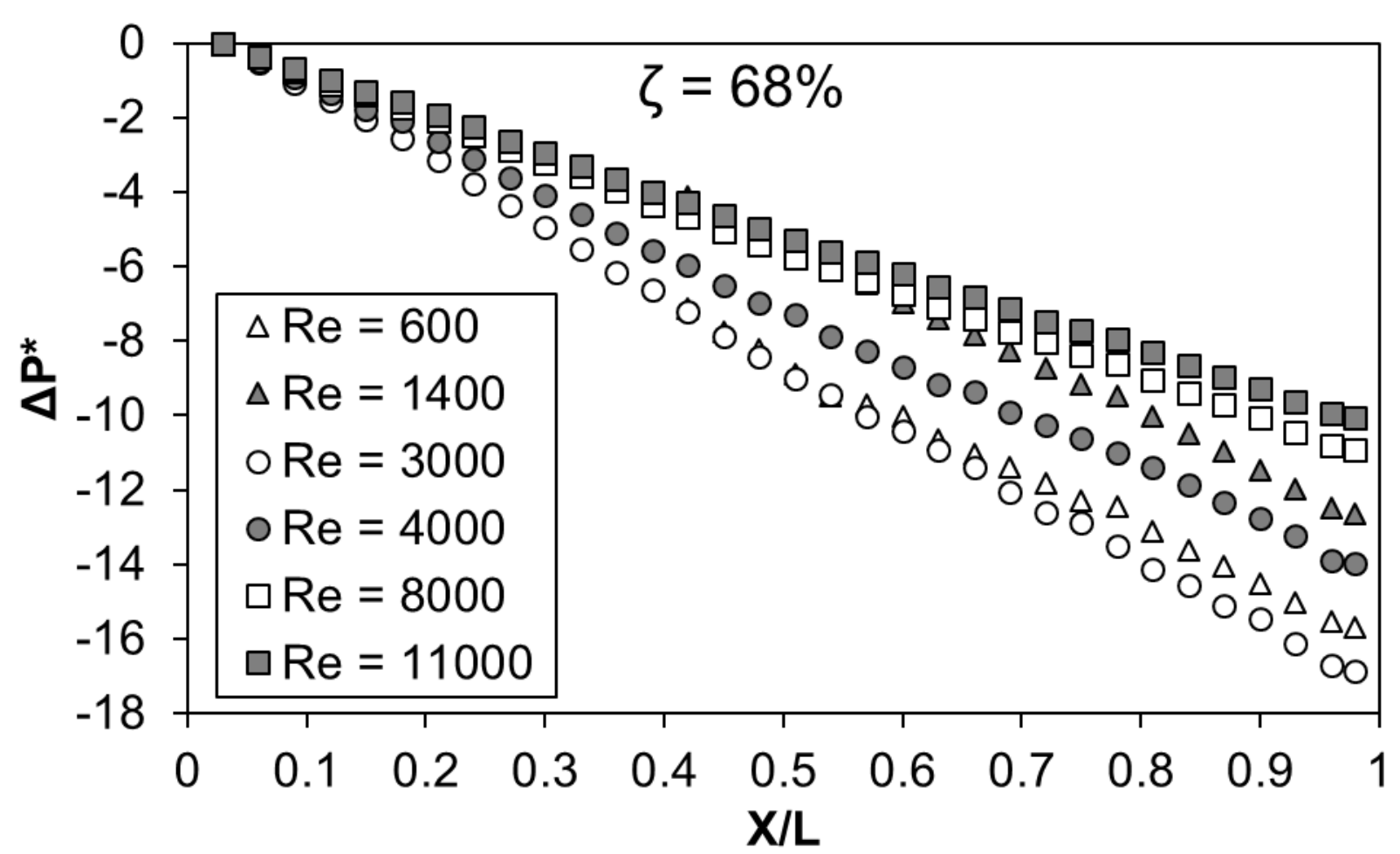

Figure 4: Normalized wall static pressure drop, $\Delta P^{*}$ along $X / L$ for the wavy screen insert with $12 \mathrm{~mm}$ period $-68 \%$ porosity at different $R e$. 
inlet on the wall. The $R e$ for the data in Fig. 4 covers the laminar to turbulent flow regime. As indicated in the figure, the distributions of $\Delta P^{*}$ along $X / L$ decrease as the $R e$ increases for the screen insert. The distributions of $\Delta P^{*}$ along $X / L$ for the screen with $48 \%$ porosity $-12 \mathrm{~mm}$ period are similar to those in Fig. 4 except the negative $\Delta P^{*}$ values for the $48 \%$ porosity screen at a given $R e$ are higher because of higher flow turbulence and resistance. The number of pores is higher in the $48 \%$ porosity screen than in the $68 \%$ porosity screen. The $\Delta P^{*}$ distribution at a Re in Fig. 4 is almost linear along $0.0<X / L<1.0$ and does not clearly identify the location of transition to the fully-developed flow in the test channel. The data for the $48 \%$ porosity screen are not presented for brevity.

$$
\Delta P^{*}=\frac{\left(P_{x}-P_{0}\right)}{0.5 \rho_{a} \cdot U^{2}}
$$

The friction factor, $f$ is determined from the $\Delta P^{*}$ distributions using the Eq. (4). The positive magnitude of pressure drop per unit length $\left(\Delta P_{x} / \Delta X\right)$ in the equation is obtained from the slope of the straight line-fit on the data of a $\Delta P^{*}$ distribution for a $R e$ based on the linearregression analysis. The line-fit is used in $X / L \geq 0.3$ and has the correlation of coefficient value of 0.99. Figure 5(a) presents the friction factor, $f$ for the entire range of $R e$ tested with both the $68 \%$ and $48 \%$ porosity screens with the wave periods of $12 \mathrm{~mm}$ and $18 \mathrm{~mm}$. The $f$ in the figure incorporates pressure drop caused by both the shear stress and form drag on the screen. As shown in Fig. 5(a), the value of $f$ decreases, in general, as the $R e$ increases for all four screens. The exception occurs for the $12 \mathrm{~mm}$ period screens when $f$ increases with $R e$ in the transition flow regime of $1000 \leq R e \leq 2700$. For the $18 \mathrm{~mm}$ wave period in Fig. 5(a), the effects of porosity are evidenced when $f$ for the $48 \%$ porosity is about twice of that for the $68 \%$ porosity screen at all Re. However, for the $12 \mathrm{~mm}$ wave period, the $f$ values are about $20 \%$ to $40 \%$ higher for the $48 \%$ porosity than for the $68 \%$ porosity screen depending on the $R e$. The higher number of pores in the $48 \%$ porosity screens causes more flow turbulence and resistance for 

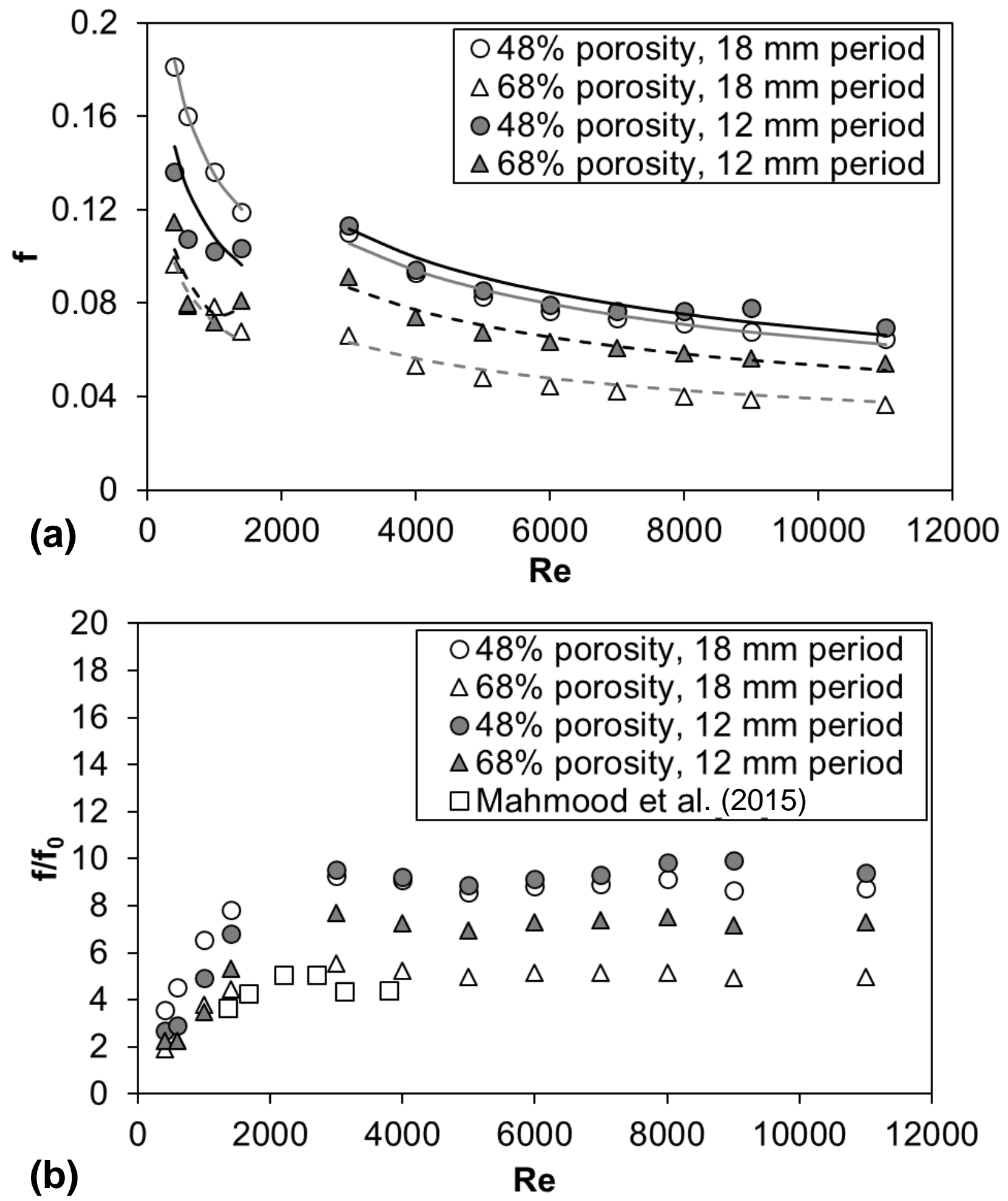

Figure 5: (a) Friction factor, $f$, and (b) Frction factor ratio, $f / f_{0}$ as dependent upon the Reynolds number, $R e$ for different screen porosities and wave periods. 
the higher $f$ values. The effects of wave period on the $f$ data are also evident in Fig. 5(a). For the $48 \%$ porosity, the $18 \mathrm{~mm}$ wave period provides about $30 \%$ to $50 \%$ higher values of $f$ than the $12 \mathrm{~mm}$ period at $R e<2000$, but the differences become negligible at $R e \geq 2700$. The effects of wave period on $f$ for the $68 \%$ porosity are somewhat opposite to those for the $48 \%$ porosity screens. The difference of $f$ values between $18 \mathrm{~mm}$ and $12 \mathrm{~mm}$ period with $68 \%$ porosity is small for a Reynolds number at $R e<2000$, but it is about $45 \%$ higher for the $12 \mathrm{~mm}$ period than for the $18 \mathrm{~mm}$ period with $68 \%$ porosity at $R e \geq 2700$. Obviously, the size and total number of pores in the screens of different wave periods at a given porosity play significant roles in the flow blockage and turbulence to affect the $f$ data in Fig. 5(a). Also, note that $f$ is much more sensitive to $R e$ change at $R e<2000$ than at $R e \geq 2700$ for the screens. The value of $f$ drops about by $40 \%$ between $400 \leq R e<2000$ and by $60 \%$ between $2700 \leq R e \leq 11000$ for the screens.

$$
f=\frac{D_{h} \cdot\left(\frac{\Delta P_{x}}{\Delta X}\right)}{0.5 \rho_{a} \cdot U^{2}}
$$

Figure 5(a) also includes the $f$-Re correlations determined from the experimental data. The solid and dotted lines in the plot represent the simple correlations provided in the $1^{\text {st }}$ column on the left in Table 2. Only two $f$-Re correlation equations are fitted on the data for the entire range of $\operatorname{Re} \leq 11,000$ at a given screen porosity and wave period. The $7^{\text {th }}$ column of Table 2 indicates the maximum difference, $\Delta f$ between the predicted value from the correlation and the experimental $f$. Note that the $f$-Re correlations for $68 \%$ and $48 \%$ porosity at a given $R e$ range and wave period are related by a simple multiplying factor.

The friction factors of Fig. 5(a) are normalized with the measured baseline friction factor, $f_{0}$ and presented in Fig. 5(b). The ratio $f / f_{0}>1.0$ signifies the pumping power enhancement in the channel with the screen compared to the smooth channel at the same Re. As shown in Fig. 5(b), the ratio $f / f_{0}$ generally increases with the $R e \leq 2700$, but then changes little as the $R e$ 
Table 2. f-Re and Nu-Re (two heated walls) correlations

\begin{tabular}{|c|c|c|c|c|c|c|c|}
\hline $\mathrm{f}$ & $\left(\mathrm{f} / \mathrm{f}_{0}\right)$ & $\mathrm{Nu}_{\text {avg }}$ & $\left(\mathrm{Nu} / \mathrm{Nu}_{0}\right)$ & $\begin{array}{c}\mathrm{Re} \\
\text { range }\end{array}$ & $\zeta, \lambda$ & $\begin{array}{c}\Delta \mathrm{f} \% \\
\Delta\left(\mathrm{f} / \mathrm{f}_{0}\right) \%\end{array}$ & $\begin{array}{c}\Delta \mathrm{Nu} \% \\
\Delta\left(\mathrm{Nu} / \mathrm{Nu}_{0}\right) \%\end{array}$ \\
\hline 1.401 & 0.0697 & 1.336 & 0.127 & & \multirow{4}{*}{$\begin{array}{c}68 \%, \\
12 \mathrm{~mm}\end{array}$} & \multirow{4}{*}{$\begin{array}{l} \pm 4 \% \\
\pm 6 \%\end{array}$} & \multirow{4}{*}{$\begin{array}{l} \pm 5 \% \\
\pm 10 \%\end{array}$} \\
\hline$\left(\operatorname{Re}^{-0.339}\right)$ & $\left(\mathrm{Re}^{0.654}\right)$ & $\left(\operatorname{Re}^{0.311}\right)$ & $\left(\operatorname{Re}^{0.355}\right)$ & $\leq 1400$ & & & \\
\hline 2.694 & 13.854 & 1.006 & 103.059 & \multirow[b]{2}{*}{$\geq 2700$} & & & \\
\hline$\left(\operatorname{Re}^{-0.405}\right)$ & $\left(\operatorname{Re}^{-0.0504}\right)$ & $\left(\operatorname{Re}^{0.405}\right)$ & $\left(\operatorname{Re}^{-0.482}\right)$ & & & & \\
\hline 1.121 & 0.0558 & 1.283 & 0.122 & & \multirow{4}{*}{$\begin{array}{l}48 \%, \\
12 \mathrm{~mm}\end{array}$} & \multirow{4}{*}{$\begin{array}{l} \pm 9 \% \\
\pm 8 \%\end{array}$} & \multirow{4}{*}{$\begin{array}{l} \pm 7 \% \\
\pm 8 \%\end{array}$} \\
\hline$\left(\operatorname{Re}^{-0.339}\right)$ & $\left(\operatorname{Re}^{0.654}\right)$ & $\left(\operatorname{Re}^{0.311}\right)$ & $\left(\operatorname{Re}^{0.355}\right)$ & $\leq 1400$ & & & \\
\hline 2.856 & 14.686 & 1.036 & 107.181 & \multirow[b]{2}{*}{$\geq 2700$} & & & \\
\hline$\left(\operatorname{Re}^{-0.405}\right)$ & $\left(\operatorname{Re}^{-0.0504}\right)$ & $\left(\operatorname{Re}^{0.405}\right)$ & $\left(\operatorname{Re}^{-0.482}\right)$ & & & & \\
\hline 0.743 & 0.0369 & 1.203 & 0.114 & \multirow[b]{2}{*}{$\leq 1400$} & \multirow{4}{*}{$\begin{array}{l}68 \%, \\
18 \mathrm{~mm}\end{array}$} & \multirow{4}{*}{$\begin{array}{l} \pm 7 \% \\
\pm 5 \%\end{array}$} & \multirow{4}{*}{$\begin{array}{l} \pm 7 \% \\
\pm 7 \%\end{array}$} \\
\hline$\left(\operatorname{Re}^{-0.339}\right)$ & $\left(\operatorname{Re}^{0.654}\right)$ & $\left(\operatorname{Re}^{0.311}\right)$ & $\left(\operatorname{Re}^{0.355}\right)$ & & & & \\
\hline 1.617 & 7.897 & 0.865 & 92.753 & \multirow[t]{2}{*}{$\geq 2700$} & & & \\
\hline$\left(\operatorname{Re}^{-0.405}\right)$ & $\left(\operatorname{Re}^{-0.0504}\right)$ & $\left(\operatorname{Re}^{0.405}\right)$ & $\left(\operatorname{Re}^{-0.482}\right)$ & & & & \\
\hline 0.841 & 0.0439 & 1.203 & 0.114 & & \multirow{4}{*}{$\begin{array}{l}48 \%, \\
18 \mathrm{~mm}\end{array}$} & \multirow{4}{*}{$\begin{array}{l} \pm 9 \% \\
\pm 5 \%\end{array}$} & \multirow{4}{*}{$\begin{array}{l} \pm 5 \% \\
\pm 9 \%\end{array}$} \\
\hline$\left(\operatorname{Re}^{-0.339}\right)$ & $\left(\operatorname{Re}^{0.654}\right)$ & $\left(\operatorname{Re}^{0.311}\right)$ & $\left(\operatorname{Re}^{0.355}\right)$ & $\leq 1400$ & & & \\
\hline 2.209 & 11.222 & 0.965 & 100.998 & & & & \\
\hline$\left(\operatorname{Re}^{-0.405}\right)$ & $\left(\operatorname{Re}^{-0.0504}\right)$ & $\left(\operatorname{Re}^{0.405}\right)$ & $\left(\operatorname{Re}^{-0.482}\right)$ & $\geq 2700$ & & & \\
\hline
\end{tabular}


increases further. Also, for either $12 \mathrm{~mm}$ or $18 \mathrm{~mm}$ wave period, the differences in $f / f_{0}$ values between the $48 \%$ and $68 \%$ porosity increase with the $R e$. The $f / f_{0}$ are smaller for the $68 \%$ porosity screens (12 $\mathrm{mm}$ and $18 \mathrm{~mm}$ periods) compared to the $48 \%$ porosity screens at all $R e$ as expected. To compare the effects of the wave period in Fig. 5(b), the $f / f_{0}$ are smaller for the $12 \mathrm{~mm}$ period than for the $18 \mathrm{~mm}$ period with $48 \%$ porosity at $R e<2000$. Then the $f / f_{0}$ are smaller for the $18 \mathrm{~mm}$ period than for the $12 \mathrm{~mm}$ period with $68 \%$ porosity at $R e>2000$. Table 2 provides the simple equations of the $\left(f / f_{0}\right)$-Re correlations and the maximum differences, $\Delta\left(f / f_{0}\right)$ between the correlations and experimental $f / f_{0}$. Here also, only two correlations of $\left(f / f_{0}\right)$ $R e$ are developed to fit the experimental data for all the $R e \leq 11,000$ at a given porosity and wave period. Figure 5(b) also compares the present data with those in Mahmood et al. (2015) at $R e<4000$. The present $f / f_{0}$ are much higher, except for the $68 \%$ porosity screen with $18 \mathrm{~mm}$ wave period, as the wavy screen in Mahmood et al. (2015) employs a much higher porosity of $80 \%$ and smaller wire diameter of $0.13 \mathrm{~mm}$ providing lower flow blockage.

\subsection{Nusselt Number with Two-Wall Heating}

The Nusselt numbers, $N u_{x}$ are reported at the thermocouple locations at $Y=101.5 \mathrm{~mm}$ on the heated wall. To maintain a minimum value of $\left(T_{w, x}-T_{m, x}\right) \approx 8{ }^{\circ} \mathrm{C}$ for low uncertainty in the $N u_{x}$ at the fully-developed locations, the average heat flux at the wall is varied depending upon the $R e$. Tests are also conducted at different heat flux levels at a $R e$, which are then repeated for different $R e$, with the screen to check for the influences of the average heat flux levels on the $N u_{x}$. The data for the different heat flux levels vary within $\pm 2 \%$.

Figure 6 provides the local Nusselt number, $N u_{x}$ distributions along the channel $X / L$ for the $68 \%$ porosity screen with the wave period of $12 \mathrm{~mm}$. The data are measured with two heated walls and shown for different $R e$. The local $N u_{x}$ in Fig. 6 at any $R e$ decrease along $X / L$ in the region $X / L \leq 0.3$ because of the thermally developing flow. The length of the thermally developing region in Fig. 6 becomes shorter as the $R e$ decreases from the turbulent to laminar 


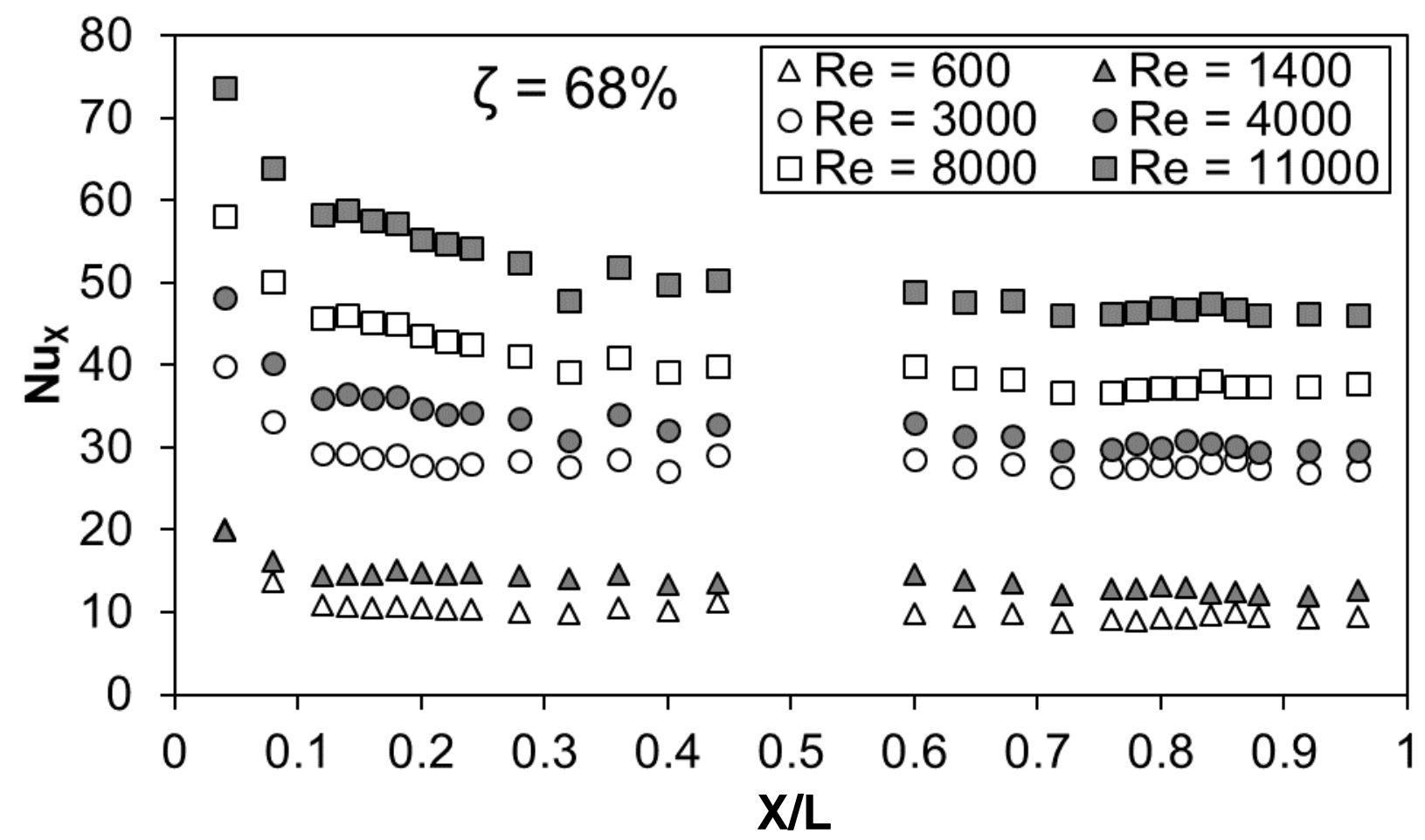

Figure 6: Local Nusselt numbers, $N u_{x}$ along $X / L$ for two heated walls for the wavy screen with $12 \mathrm{~mm}$ period $-68 \%$ porosity at different $R e$. 
flow. The screen generated local turbulence aids the already developed turbulent flow as it enters the test section causing the higher heat transfer coefficients in $X / L \leq 0.3$ for $R e>4000$. For the $R e \leq 3000$, the laminar flow is turbulated by the screen as it enters the test section causing the flow to be thermally developed in a short distance of $X / L \leq 0.15$. In the region $X / L$ $>0.3$, the $N u_{x}$ values then change little along $X / L$ for all the $R e$ as the flow becomes thermally developed. The distributions of $N u_{x}$ in Fig. 6 increase with the $R e$ and mass flux as expected. Note that the $N u_{x}$ distributions as the $R e$ changes for the screen with $48 \%$ porosity $-12 \mathrm{~mm}$ period are almost similar to those in Fig. 6 and not presented for brevity. Mahmood et al. (2015) show the variations of $N u_{x}$ along $Y$ inside a wave period are insignificant.

The local Nusselt numbers inside the fully developed region $(X / L \geq 0.6)$ as those in Fig. 6 are averaged to be presented as the $N u_{\text {avg }}$ in Fig. 7 (a) as the $R e$ varies for different screen porosities and wave periods. The average $N u_{a v g}$ increases with $R e$ for all the screen inserts in Fig. 7(a). Between $400 \leq R e<2000$ and between $2700 \leq R e \leq 11000$ the $N u_{\text {avg }}$ increases by about $66 \%$ for all four screens indicating the highly sensitive $N u_{a v g}$ to the $R e$ change in the low range of Reynolds numbers. The effects of screen porosity on the $N u_{\text {avg }}$ for the wave period of $18 \mathrm{~mm}$ or $12 \mathrm{~mm}$ are only evident at $R e \geq 2700$ where the $48 \%$ porosity screens provide higher $N u_{\text {avg }}$ than the $68 \%$ porosity screens. The effects of wave period in Fig. 7(a) are only evident marginally for the $68 \%$ porosity screens as the $12 \mathrm{~mm}$ period provides consistently higher $N u_{a v g}$ than the $18 \mathrm{~mm}$ period at $R e \geq 2700$. In the laminar range of $R e<2000$, the effects of porosity and wave period on the $N u_{a v g}$ are insignificant. The dotted and solid lines in Fig. 7(a) represent the $N u$-Re correlations developed from the $N u_{\text {avg }}$ data in the same figure. The simple equations of the correlations are provided in the $3^{\text {rd }}$ column of Table 2 . The last column of the table also provides the maximum differences, $\Delta N u$ between the correlations and experimental $N u_{\text {avg. }}$. Here also, only two $\mathrm{Nu}$ - $\mathrm{Re}$ correlations are fitted through the data for the entire $R e$ range. A simple 

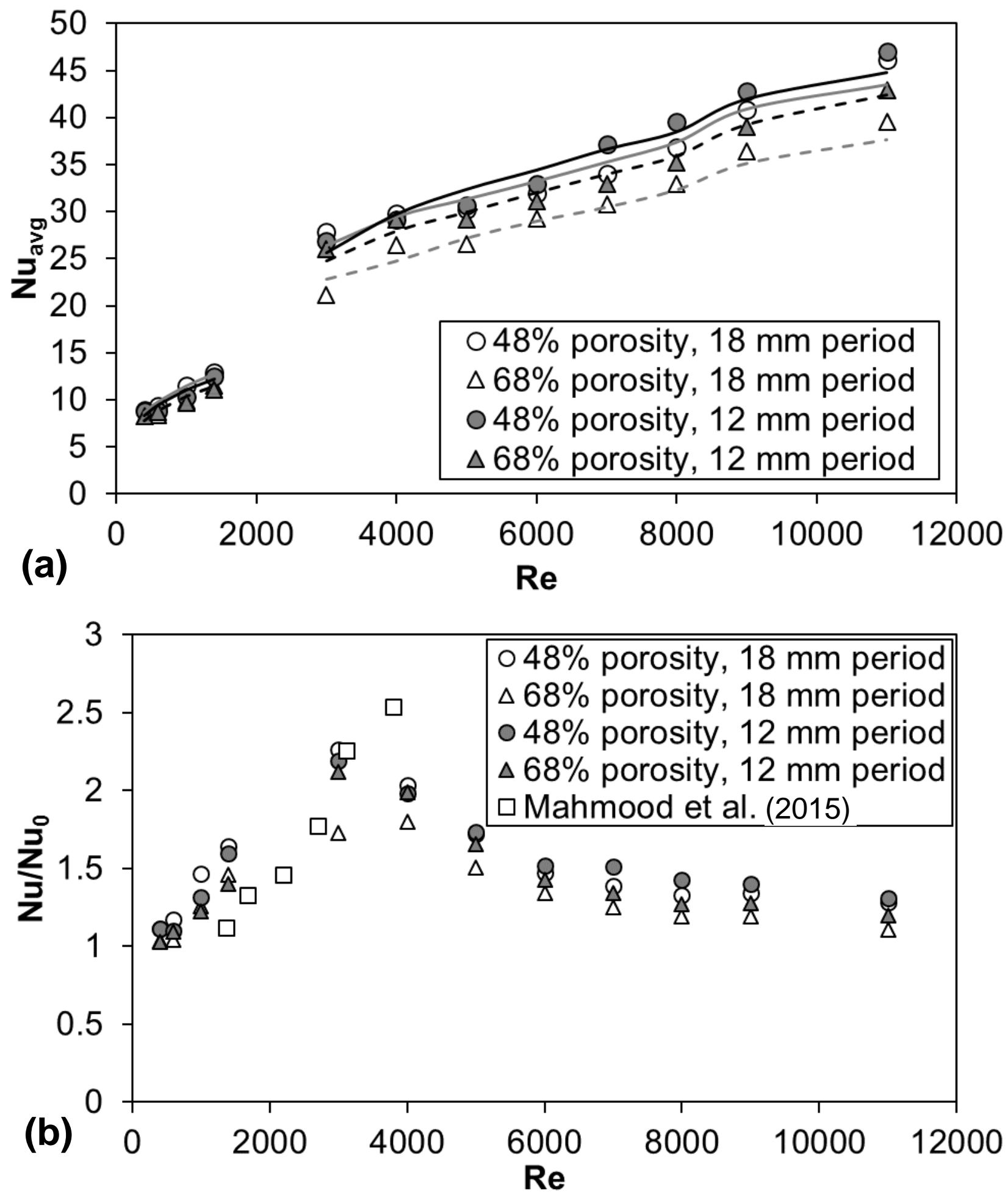

Figure 7: For two heated walls: (a) average Nusselt numbers, $N u_{\text {avg }}$, and (b) average ratio $N u / N u_{0}$ as $R e$, screen porosity, and wave period vary. 
multiplying factor can relate the $\mathrm{Nu}$-Re correlation of $68 \%$ porosity with that of $48 \%$ porosity in Table 2 at a given $R e$ range and wave period.

The average $N u_{\text {avg }}$ are normalised by the measured baseline $N u_{0}$ at the corresponding $R e$ and presented as $\mathrm{Nu} / \mathrm{Nu} u_{0}$ in Fig. 7(b). The fully-developed $\mathrm{Nu} u_{0}$ at a given $R e$ in the smooth channel is also obtained with two heated walls at a uniform heat flux. The ratio $N u / N u_{0}>1.0$ then indicates the heat transfer enhancement with the screen at a given $R e$ and temperature difference of $\left(T_{w, x}-T_{m, x}\right)$. Figure $7(\mathrm{~b})$ presents the $N u / N u_{0}$ for all four screens over the entire $R e$ range. For all the screens, $N u / N u_{0}$ increases with $R e \leq 2700$ and then decreases as $R e$ increases beyond 3000. The effects of porosity and wave period on $N u / N u_{0}$ in Fig. 7(b) are marginal. The differences in $N u / N u_{0}$ between the $68 \%$ and $48 \%$ porosity screens or the $12 \mathrm{~mm}$ and $18 \mathrm{~mm}$ screens are generally less than $15 \%$ for all the $R e$ except at the $R e=2700$. The maximum of $N u / N u_{0}=2.3$ and minimum of $N u / N u_{0}=1.1$ for two heated walls are achieved at $R e=2700$ and 400, respectively. The $\left(\mathrm{Nu} / \mathrm{Nu} u_{0}\right)-R e$ correlations fitting the data in Fig. $7(\mathrm{~b})$ and the maximum differences between the correlations and experiments, $\Delta\left(N u / N u_{0}\right)$ are provided in Table 2. Figure 7(b) shows the present $N u / N u_{0}$ ratios are generally higher than those in Mahmood et al. (2015) except at the $R e \approx 4000$ where the present $N u / N u_{0}$ values are much lower.

\subsection{Nusselt Number with One-Wall Heating}

Figure 8 provides the local Nusselt numbers, $N u_{\mathrm{x}}$ along $X / L$ for the $68 \%$ porosity screen with the wave period of $12 \mathrm{~mm}$. The distributions are shown for one heated wall as the $R e$ varies. The wall heat flux level is varied based on the $R e$ to maintain a difference of $\left(T_{w, x}-\right.$ $T_{m, x} \geq 8^{\circ} \mathrm{C}$. The distributions of $N u_{x}$ at a $R e$ in Fig. 8 change little at $X / L \geq 0.4$ where the flow is thermally developed. However, the $X / L$ length of the thermal development, where $N u_{x}$ varies with $X / L$, decreases with the $R e$. The $N u_{x}$ distributions in Fig. 8 also increase with the $R e$ and 


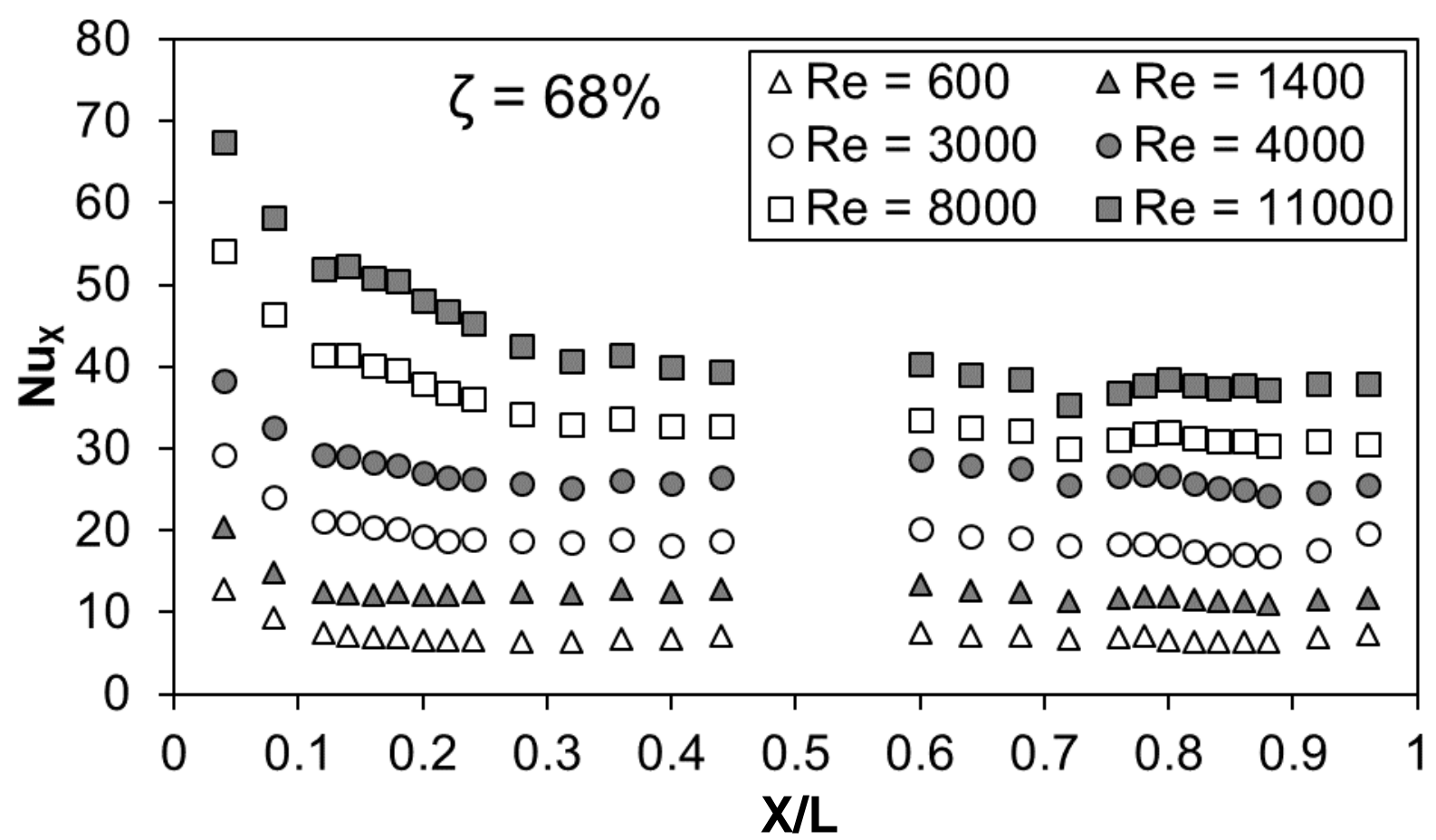

Figure 8: Local Nusselt numbers, $N u_{x}$ along $X / L$ for one heated wall for the wavy screen with $12 \mathrm{~mm}$ period $-68 \%$ porosity at different $R e$. 
are similar for the screen with $48 \%$ porosity $-12 \mathrm{~mm}$ period at any $R e$. The data for the $48 \%$ screen are excluded for brevity.

The averages of the local Nusselt numbers inside the fully-developed region $(X / L \geq 0.6)$ with one heated wall are presented as $N u_{\text {avg }}$ in Fig. 9(a) as the Re, screen porosity, and wave period vary. The $N u_{\text {avg }}$ increases with the $R e$ for all four screens in the figure. Between $400 \leq$ $R e \leq 2700$ the $N u_{\text {avg }}$ increases by about $180 \%$ for the screens. In comparisons, between $4000 \leq$ $R e \leq 11000$ the $N u_{\text {avg }}$ increases about by $60 \%$ for the $12 \mathrm{~mm}$ period- $48 \%$ porosity screen and within $30 \%$ for the other three screens in Fig. 9(a) indicating the $N u_{a v g}$ to be highly sensitive to the $R e$ change in the low range of Reynolds numbers. The distributions of $N u_{a v g}$ versus $R e$ differ little at most of the $R e$ as the wave period or porosity changes. Table 3 provides the equations for $\mathrm{Nu}$-Re correlations fitting through the data in Fig. 9(a) for one heated wall. The solid and dotted lines in the figure compare the correlations with the experiments. The last column of Table 3 indicates the maximum differences, $\Delta N u$ between the correlations and experiments.

The ratios of average Nusselt number to baseline Nusselt number, $\mathrm{Nu} / \mathrm{Nu} u_{0}$ with one-wall heating are presented in Fig. 9(b) for different $R e$, screen porosity, and wave period. The fullydeveloped $\mathrm{Nu} u_{0}$ are measured with one-wall heating at the corresponding $R e$. The average $N u / N u_{0}$ increases with the $R e \leq 4000$ and then decreases between $5000 \leq R e \leq 11000$ with one heated wall. The comparisons of $N u / N u_{0}$ between the screen porosities or between the wave periods in Fig. 9(b) indicate a maximum difference of less than $15 \%$ as the porosity or wave period changes at a $R e$. The maximum of $N u / N u_{0}=2.8$ and minimum of $N u / N u_{0}=1.2$ for one heated wall are achieved at $R e=4000$ and 400, respectively. Table 3 provides the simple $\left(\mathrm{Nu} / \mathrm{Nu} u_{0}\right)-\mathrm{Re}$ correlations predicting the data in Fig. 9(b) along with the maximum differences, $\Delta\left(\mathrm{Nu} / \mathrm{N} u_{0}\right)$ from the experiments. The present experimental $N u / N u_{0}$ in Fig. 9(b) are higher than those in Mahmood et al. (2015) for one heated wall at $1000<\operatorname{Re}<4000$. 
Table 3. Nu-Re (one heated wall) correlations

\begin{tabular}{|c|c|c|c|c|}
\hline $\mathrm{Nu}_{\text {avg }}$ & $\left(\mathrm{Nu} / \mathrm{Nu}_{0}\right)$ & Re range & $\zeta, \lambda$ & $\begin{array}{c}\mathrm{Nu} \% \\
\Delta \mathrm{Nu} / \mathrm{Nu}_{0} \%\end{array}$ \\
\hline 0.178 & 0.110 & & \multirow{4}{*}{$\begin{array}{l}68 \%, \\
12 \mathrm{~mm}\end{array}$} & \multirow{4}{*}{$\begin{array}{l} \pm 7 \% \\
\pm 8 \%\end{array}$} \\
\hline$\left(\operatorname{Re}^{0.576}\right)$ & $\left(\operatorname{Re}^{0.395}\right)$ & $\leq 2700$ & & \\
\hline 1.307 & 344.537 & \multirow[b]{2}{*}{$\geq 4000$} & & \\
\hline$\left(\operatorname{Re}^{0.357}\right)$ & $\left(\operatorname{Re}^{-0.605}\right)$ & & & \\
\hline 0.191 & 0.111 & & \multirow{4}{*}{$\begin{array}{l}48 \%, \\
12 \mathrm{~mm}\end{array}$} & \multirow{4}{*}{$\begin{array}{l} \pm 9 \% \\
\pm 9 \%\end{array}$} \\
\hline$\left(\operatorname{Re}^{0.576}\right)$ & $\left(\operatorname{Re}^{0.395}\right)$ & $\leq 2700$ & & \\
\hline 1.373 & 351.427 & \multirow[b]{2}{*}{$\geq 4000$} & & \\
\hline$\left(\operatorname{Re}^{0.357}\right)$ & $\left(\operatorname{Re}^{-0.605}\right)$ & & & \\
\hline 0.178 & 0.0971 & \multirow{2}{*}{$\leq 2700$} & \multirow{4}{*}{$\begin{array}{l}68 \%, \\
18 \mathrm{~mm}\end{array}$} & \multirow{4}{*}{$\begin{array}{l} \pm 7 \% \\
\pm 10 \%\end{array}$} \\
\hline$\left(\operatorname{Re}^{0.576}\right)$ & $\left(\operatorname{Re}^{0.395}\right)$ & & & \\
\hline 1.242 & 344.537 & \multirow[t]{2}{*}{$\geq 4000$} & & \\
\hline$\left(\operatorname{Re}^{0.357}\right)$ & $\left(\operatorname{Re}^{-0.605}\right)$ & & & \\
\hline 0.175 & 0.0971 & & \multirow{4}{*}{$\begin{array}{l}48 \%, \\
18 \mathrm{~mm}\end{array}$} & \multirow{4}{*}{$\begin{array}{l} \pm 8 \% \\
\pm 9 \%\end{array}$} \\
\hline$\left(\operatorname{Re}^{0.576}\right)$ & $\left(\operatorname{Re}^{0.395}\right)$ & $\leq 2700$ & & \\
\hline 1.242 & 344.537 & \multirow[b]{2}{*}{$\geq 4000$} & & \\
\hline$\left(\operatorname{Re}^{0.357}\right)$ & $\left(\operatorname{Re}^{-0.605}\right)$ & & & \\
\hline
\end{tabular}



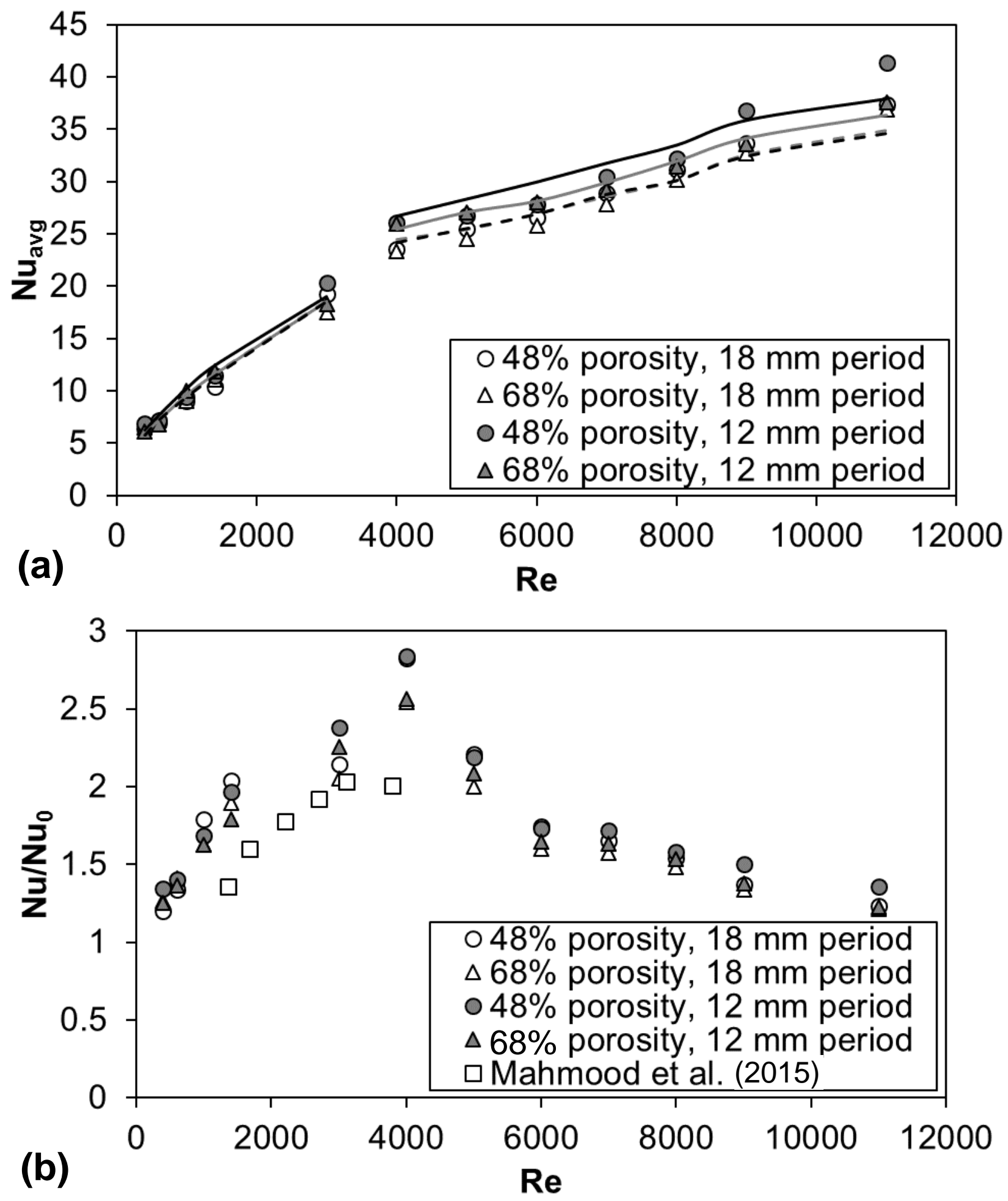

Figure 9: For one heated wall: (a) average Nusselt numbers, $N u_{\text {avg }}$, and (b) average ratio $\mathrm{Nu} / \mathrm{Nu} u_{0}$ as $R e$, screen porosity, and wave period vary. 


\subsection{Thermal Performance}

The thermal performance index, $\left(\mathrm{Nu} / \mathrm{Nu} u_{0}\right) /\left(f / f_{0}\right)^{(1 / 3)}$ in Fig. 10 defined by Webb and Kim (2005) and Gee and Webb (1980) for the screen channel is computed from the $f / f_{0}$ and average $\mathrm{Nu} / \mathrm{Nu}$ o data presented earlier. The definition of the performance index is based on the three basic design objectives of the heat exchanger: (i) reduced heat transfer area, (ii) enhanced heat transfer rate, and (iii) reduced pumping power, all relative to the smooth channel. Figures 10 (a, b) provide the performance index for all four screens with two and one heated wall, respectively, as the $R e$ varies. For good thermal performance, the $\left(N u / N u_{0}\right) /\left(f / f_{0}\right)^{(1 / 3)} \geq 1.0$ are expected (Mahmmod et al., 2015, and Gee and Webb, 1980).

The thermal performance index for two heated walls in Fig. 10(a) increases with the $R e \leq$ 4000 and then decreases as the $R e$ increases between $4000<R e \leq 11000$ for all the screens. Between $400 \leq R e \leq 4000$ the performance index increases by $42 \%$ at the maximum for the screens. However, the values of $\left(N u / N u_{0}\right) /\left(f / f_{0}\right)^{(1 / 3)}$ are close to or more than 1.0 in Fig. 10(a) only at $R e=3000-4000$. The effects of screen porosity at a wave period or of wave period at a porosity are marginal at $R e \leq 4000$ in Fig. 10(a). The thermal performance indexes for one heated wall are shown in Fig. 10(b) and have similar distributions to the cases of two heated walls as the Re changes. Most of the values of $\left(N u / N u_{0}\right) /\left(f / f_{0}\right)^{(1 / 3)}$ for one heated wall in Fig. 10(b) are close to or more than 1.0 between $1000 \leq R e \leq 5000$ with the maximum value of about 1.5 at $R e=4000$. The $\left(N u / N u_{0}\right) /\left(f / f_{0}\right)^{(1 / 3)}$ for one heated wall for the screens with the 18 $\mathrm{mm}$ wave period are generally higher than the other two screens for most of the $R e$. The maximum difference in $\left(N u / N u_{0}\right) /\left(f / f_{0}\right)^{(1 / 3)}$ between the $18 \mathrm{~mm}$ wave period-68\% porosity screen and others is about $16 \%$ in Fig. 10(b) at $R e=1400$ and 4000. Figures $10(a, b)$ show the performance indexes of the present cases differ from those of Mahmood et al. (2015) for one heated wall at all the $R e<4000$. Note, the thermal performance between the two heated walls and one heated wall should not be compared with each other as the thermal boundary conditions 
as well as the intended applications of the two cases are different (Mahmood et al., 2015). However, the comparisons of the results between the present cases and those of Mahmood et al. (2015) suggest the large change in the porosity and pore geometry of the wavy screen may affect the thermal performance index significantly over a wide range of $R e$.

\section{Summary and Conclusions}

The pressure drop, friction factors, and heat transfer coefficients are measured in a rectangular channel when the wavy porous screens are employed as inserts. The sinusoidal wave construction of the screen employs two different porosities and wave periods: $68 \%$ porosity- $12 \mathrm{~mm}$ period, $48 \%$ porosity- $12 \mathrm{~mm}$ period, $68 \%$ porosity- $18 \mathrm{~mm}$ period, and $48 \%$ porosity-18 $\mathrm{mm}$ period. The peak-to-peak height of the sinusoid is $5 \mathrm{~mm}$ for the screens and makes only line contacts with the channel walls without any bonding or soldering. The wave vectors are placed parallel to the channel mean flow. The screen construction provides three structural advantages- supports channel walls, has light weight, and makes the channel modular because it is easily replaceable. The wavy screen thus contends to replace the porous foams having very high pressure drops. The inlet Reynolds number for the experiments varies from 400 to 11,000 . For the heat transfer experiments, the channel walls touching the screen tips are heated to simulate the channel of a flat plate heat exchanger. The measurements with one heated wall simulate the conditions of the solar panels and electronic cooling. The thermohydraulic performance of the screen channel are then quantified by comparing the measured data between the screen channel and smooth channel. The results are summarized as follows.

(i) The friction factor, $f$ and friction factor ratio, $f / f_{0}$ in the screen channel depends strongly on the Reynolds number $(R e)$, screen porosity, and wave period of screen. While the friction factor decreases as the Reynolds number increases, the $f / f_{0}$ ratio increases with the $R e \leq 2700$. The ratios, $f / f_{0}$ then change little at $R e>2700$. Both $f$ and $f / f_{0}$ decrease as the screen porosity increases from $48 \%$ to $68 \%$. The wave period 
of the screen affects both $f$ and $f / f_{0}$ at $R e<2000$ for the $48 \%$ porosity and at $R e \geq 2700$ for the $68 \%$ porosity.

(ii) For two heated walls or one heated wall, the fully-developed average Nusselt numbers, $N u_{\text {avg }}$ and ratios of screen to smooth channel Nusselt numbers, $N u / N u_{0}$ depend strongly on the Reynolds number. The effects of screen porosity and wave period are marginal on $N u_{\text {avg }}$ and $N u / N u_{0}$. While the $N u_{\text {avg }}$ increase with $R e$ for all the screens, the average $\mathrm{Nu} / \mathrm{Nu} u_{0}$ ratios increase with the $R e \leq 4000$ and then decrease as the $R e$ increases. The two screens with the $48 \%$ porosity generally provide slightly higher $N u_{a v g}$ and $N u / N u_{0}$ than the $68 \%$ porosity screens.

(iii) The thermal performance index, $\left(N u / N u_{0}\right) /\left(f / f_{0}\right)^{(1 / 3)}$ is sensitive to the Reynolds number for all four screens and increases with the $R e \leq 4000$ and decreases as the $R e$ increases further. The desirable $\left(\mathrm{Nu} / \mathrm{Nu} u_{0}\right) /\left(f / f_{0}\right)^{(1 / 3)} \geq 1.0$ is achieved when $3000 \leq R e \leq 4000$ for two heated walls and $1000 \leq R e \leq 5000$ for one heated wall. The influences of the wave period and porosity on the $\left(N u / N u_{0}\right) /\left(f / f_{0}\right)^{(1 / 3)}$ seem to be marginal for the present screens.

(iv) In general, the $f, f / f_{0}, N u, N u / N u_{0}$, and thermal performance index for all four screens are very sensitive to the Reynolds number change in the range of $R e \leq 4000$.

In conclusion, the sinusoidal screen inserts in the channels of a flat plate heat exchanger can provide desirable effects on the heat transfer enhancements $\left(\mathrm{Nu} / \mathrm{Nu} u_{0}>1.0\right)$ only for the range of Reynolds number tested. The wire diameter and pore geometry of the mesh screen can significantly influence the thermal performance and pressure penalty in the channel based on the present investigations and Mahmood et al. (2015). The present results are thus beneficial to the design of porous inserts for the heat exchangers operating over a wide range of flow rates. 


\section{Acknowledgment}

The authors gratefully acknowledge the financial contributions of the NRF South Africa and the University of Pretoria, South Africa for the research.

\section{References}

1. Alhusseny, A., Turan, A., and Nasser, A., Developing Convective Flow in a Square Channel Partially Filled with a High Porosity Metal Foam and Rotating in a Parallel-Mode, International J. Heat and Mass Transfer, vol. 90, pp. 578-590, 2015.

2. Beckwith, T.G., Marangoni, R.D., and Lienhard, J.H., Mechanical Measurements, sixth ed., New Jersey: Pearson Prentice Hall, pp. 42-45, 54-59, 2007.

3. Chen, C.-C., Huang, P.-C., and Hwang, H.-Y., Enhanced Forced Convective Cooling of Heat Sources by Metal-Foam Porous Layers, International J. Heat and Mass Transfer, vol. 58, pp. 356-373, 2013.

4. Davari, A., and Maerefat, M., Numerical Analysis of Fluid Flow and Heat Transfer in Entrance and Fully Developed Regions of a Channel with Porous Baffles, J. Heat Transfer, vol. 138, pp. 0626011-06260110, 2016.

5. Gee, D.L., and Webb, R.L., Forced Convection Heat Transfer in Helically Rib-Roughened Tubes, International J. Heat Mass Transfer, vol. 23, pp. 1127-1136, 1980.

6. Hamdan, M., and Al-Nimr, M.A., The Use of Porous Fins for Heat Transfer Augmentation in Parallel-Plate Channels, Transport in Porous Media, vol. 84, no. 2, pp. 409-420, 2010.

7. Hobold, G.M., and da Silva, A.K., Two-Dimensional Porosity Optimization of Saturated Porous Media for Maximal Thermal Performance Under Forced Convection, International J. Heat and Mass Transfer, vol. 108, pp. 1689-1701, 2017. 
8. International Standard, ISO 5167-1980(E), Measurement of Fluid Flow by Means of Orifice Plates, Nozzles and Venture Tubes Inserted in Circular Cross-Section Conduits Running Full, 1980-07-15, 1980.

9. Kays, W.M. and London, A.L., Compact Heat Exchangers, second ed., New York: McGrawHill, USA, pp. 155 and 219, 1964.

10. Kays, W.M. and Crawford, M. E., Convective Heat and Mass Transfer, third ed., New York: McGraw-Hill Inc., USA, pp. 79, 125, 249, and 332, 1993.

11. Kim, S.Y., Paek, J.W., and Kang, B.H., Flow and Heat Transfer Correlations for Porous Fin in a Plate-Fin Heat Exchanger, J. Heat Transfer, vol. 122, pp. 572-578, 2000.

12. Lu, W., Zhang, T., and Yang, M., Analytical Solution of Forced Convective Heat Transfer in Parallel-Plate Channel Partially Filled with Metallic Foams, International J. Heat and Mass Transfer, vol. 100, pp. 718-727, 2016.

13. Maerefat, M., Mahmoudi, S.Y., and Mazaheri, K, Numerical Simulation of Forced Convection Enhancement in a Pipe by Porous Inserts, Heat Transfer Engineering, vol. 32, no. 1, pp. 45-56, 2011.

14. Mahmood, G.I., Simonson, C.J., and Besant, R.W., Experimental Pressure Drop and Heat Transfer in a Rectangular Channel with a Sinusoidal Porous Screen, J. Heat Transfer, vol. 137, no. 4, pp. 0426011-04260111, 2015.

15. Moffat, R.J., Describing the Uncertainties in Experimental Results, Experimental Thermal and Fluid Science, vol. 1, no. 1, pp. 3-17, 1988.

16. Mohammadian, S.K., and Zhang, Y., Temperature Uniformity Improvement of an AirCooled High-Power Lithium-Ion Battery Using Metal and Non-Metal Foams, J. Heat Transfer, vol. 138, pp. 1145021-1145024, 2016. 
17. Mohammadian, S.K., Rassoulinejad-Mousavi, S.M., and Zhang, Y., Thermal Management Improvement of an Air-Cooled High-Power Lithium-Ion Battery by Embedding Metal Foam, J. Power Sources, vol. 296, pp. 305-313, 2015.

18. Park, S.-H., Kim, T.H., and Jeong, J.H., Experimental Investigation of the Convective Heat Transfer Coefficient for Open-Cell Porous Metal Fins at Low Reynolds Numbers, International J. Heat and Mass Transfer, vol. 100, pp. 608-614, 2016.

19. Pavel B.I., and Mohamad A.A., Experimental Investigation of the Potential of Metallic Porous Inserts in Enhancing Forced Convective Heat Transfer, J. Heat Transfer, vol. 126, pp. 540-545, 2004.

20. Pavel B.I., and Mohamad A.A., An Experimental and Numerical Study on Heat Transfer Enhancement for Gas Heat Exchangers Fitted with Porous Media, International J. Heat and Mass Transfer, vol. 47, pp. 4939-4952, 2004.

21. Santos, N.B., and de Lemos, M.J.S., Flow and Heat Transfer in a Parallel-Plate Channel with Porous and Solid Baffles, Numerical Heat Transfer, Part A, vol. 49, pp. 471-494, 2006.

22. Torii, S. and Yang, W.-J., Thermal-Fluid Flow Transport Phenomenon Over SlotPerforated Flat Plates Placed in Narrow Channel, J. Thermophysics and Heat Transfer, vol. 21, no. 2, pp. 346-351, 2007.

23. Wang, B., Hong, Y., Hou, X., Xu, Z., Wang, P., Fang, X., and Ruan, X., Numerical Configuration Design and Investigation of Heat Transfer Enhancement in Pipes Filled with Gradient Porous Materials, Energy Conversion and Management, pp. 206-215, 2015.

24. Webb, R.L. and Kim, N.-H., Principles of Enhanced Heat Transfer, second ed., New York: Taylor and Francis, USA, pp.57-60, 210-227, 246-269, 2005. 